\title{
Effects of propionate concentration on short-term metabolism in liver explants from dairy cows in the postpartum period
}

\author{
Katherine M. Kennedy, ${ }^{1 *} \odot$ Shawn S. Donkin, ${ }^{2} \odot$ and Michael S. Allen ${ }^{1} \dagger[0$ \\ ${ }^{1}$ Department of Animal Science, Michigan State University, East Lansing 48824 \\ ${ }^{2}$ Department of Animal Sciences, Purdue University, West Lafayette, IN 47907
}

\begin{abstract}
Our objective was to determine the temporal effects of increasing supply of propionate on propionate metabolism in liver tissue of dairy cows in the postpartum (PP) period. A total of 6 dairy cows [primiparous: $\mathrm{n}=$ 3, $9.00 \pm 1.00 \mathrm{~d}$ PP (mean $\pm \mathrm{SD}$ ) and multiparous: $\mathrm{n}=$ $3 ; 4.67 \pm 1.15 \mathrm{~d} \mathrm{PP}]$ were biopsied for liver explants in a block-design experiment. Explants were treated with 3 concentrations of $\left[{ }^{13} \mathrm{C}_{3}\right]$ sodium propionate of 1,2 , or 4 $\mathrm{m} M$. Explants were incubated in $2 \mathrm{~mL}$ of Medium 199 supplemented with $1 \%$ BSA, $0.6 \mathrm{~m} M$ oleic acid, $2 \mathrm{mM}$ sodium L-lactate, $0.2 \mathrm{~m} M$ sodium pyruvate, and 0.5 $\mathrm{m} M$ L-glutamine at $38^{\circ} \mathrm{C}$ and sampled at $0.5,15$, and 60 min. Increasing the concentration of $\left[{ }^{13} \mathrm{C}_{3}\right]$ propionate increased total ${ }^{13} \mathrm{C} \%$ enrichment of propionyl coenzyme A ( $\mathrm{CoA})$, succinate, fumarate, malate, and citrate with time. Concentration of propionate did not affect total ${ }^{13} \mathrm{C} \%$ enrichment of hepatic glucose or acetyl CoA, but total ${ }^{13} \mathrm{C} \%$ enrichment increased with time for hepatic glucose. The ${ }^{13} \mathrm{C}$ labeling from propionate was incorporated into acetyl $\mathrm{CoA}$, but increased concentrations of propionate did not result in greater labeling of acetyl CoA. However, increases in ${ }^{13} \mathrm{C} \%$ enrichment of $[\mathrm{M}+4]$ citrate and $[\mathrm{M}+5]$ citrate concentrations of $\left[{ }^{13} \mathrm{C}_{3}\right]$ propionate indicate propionate conversion to acetyl CoA and subsequent entry of acetyl CoA into the tricarboxylic acid cycle in dairy cows in the PP period. This research presents evidence that despite an increase in hepatic acetyl CoA concentration and general consensus on the upregulation of gluconeogenesis of dairy cows during the PP period, carbon derived from propionate contributes to the pool of acetyl CoA, which increases as concentration of propionate increases, in addition to
\end{abstract}

Received May 17, 2020

Accepted July 1, 2020.

*Current address: Institute of Nutritional Physiology ("Oskar Kellner"), Leibniz Institute for Farm Animal Biology (FBN), 18196 Dummerstorf, Germany.

†Corresponding author: allenm@msu.edu stimulating oxidation of acetyl CoA from other sources. Because of the hypophagic effects of propionate, but importance of propionate as a glucose precursor, a balance of propionate supply to dairy cows could lead to improvements in dry matter intake, and subsequently, health and production in dairy cows.

Key words: propionate, hepatic metabolism, dairy cow

\section{INTRODUCTION}

Dairy cows in the immediate postpartum (PP) period experience negative energy balance from increased demands for milk production (Bauman and Currie, 1980). These animals exhibit a suppression in appetite (Allen and Piantoni, 2013), exacerbating the negative energy balance. To increase energy intake, cereal grains containing starch are frequently substituted for fiber sources in the diet of early-lactation cows. Propionic acid produced from starch fermentation is a primary glucose precursor in dairy cows. However, propionate has hypophagic effects on dairy cows in the PP period (Allen, 2000) and has been shown to decrease DMI to a greater extent than the glucose precursors lactate (Gualdrón-Duarte and Allen, 2018) and glycerol (Gualdrón-Duarte and Allen, 2017).

The metabolic pathway of propionate in the liver of ruminants is well-established. However, the majority of work examining propionate metabolism in ruminants was conducted in cell or explant cultures from calves (Aiello et al., 1989; Donkin and Armentano, 1995), goats (Aiello and Armentano, 1987; Demigné et al., 1991), or cows past the PP period (Drackley et al., 1991; Knapp et al., 1992; Zhang et al., 2015). Dairy cows in the PP period are in a lipolytic state with higher concentrations of hepatic acetyl CoA compared with late-lactation dairy cows (Piantoni et al., 2015), and the majority of this pool is derived from hepatic $\beta$-oxidation of circulating plasma free fatty acids. Additionally, gluconeogenesis and pyruvate carboxylase, the enzyme responsible for converting pyruvate to oxaloacetate, are upregulated during this stage of lacta- 
tion (Greenfield et al., 2000; Aschenbach et al., 2010). Therefore, the majority of propionate is used for glucose synthesis. However, propionate might contribute to the pool of acetyl CoA as well. As part of gluconeogenesis, carbon derived from propionate exits the tricarboxylic acid (TCA) cycle as malate and converts to phosphoenolpyruvate through oxaloacetate. Phosphoenolpyruvate can either continue through gluconeogenesis to synthesize glucose or convert to pyruvate. Pyruvate, in turn, can be decarboxylated to acetyl CoA through the pyruvate dehydrogenase complex. Although elevated acetyl CoA and ATP concentrations inhibit the pyruvate dehydrogenase complex, a recent study using liver slices from early lactation dairy cows ( 12 DIM) incubated for $2 \mathrm{~h}$ with labeled pyruvate and unlabeled propionate reported an increase in flux of pyruvate to acetyl CoA (Garcia et al., 2015). Likewise, the shortterm presence of unlabeled propionate reduced the flux of radiolabeled lactate to glucose in bovine hepatocytes (Donkin and Armentano, 1994), indicating offsetting changes in pyruvate metabolism. In a previous study in our laboratory, potential metabolic bottlenecks of propionate metabolism, such as succinate dehydrogenase and enzymes sensitive to NADH concentrations, were identified within 20 min of a pulse dose of propionic acid, including an increase in pyruvate concentration (Kennedy and Allen, 2019a). Understanding the shortterm hepatic metabolism of propionate in dairy cows in the PP period may help to develop improved feeding and management strategies during this period.

Our objective was to determine the direct, shortterm temporal effects of increasing concentrations of propionate on propionate metabolism in liver tissue of dairy cows in the PP period. We hypothesized that the majority of propionate is used for synthesis of glucose, but that increasing the concentration of propionate will increase carbon derived from propionate converted to acetyl CoA for oxidation in the TCA cycle.

\section{MATERIALS AND METHODS}

The Institutional Animal Care and Use Committee at Michigan State University approved all animal experimental procedures for this experiment.

\section{Experimental Design, Treatments, and Animal Management}

Six dairy cows (3 primiparous and 3 multiparous) were used in a block-design experiment. Cows were housed in tiestalls at the Michigan State University Dairy Cattle Teaching and Research Center (East Lansing, Michigan). Animals were blocked by parity and fed a common ration formulated to contain $27 \%$ NDF, $23 \%$ forage NDF, $25 \%$ starch, and $18.4 \% \mathrm{CP}$ that consisted of corn silage, ground corn, soybean meal, alfalfa silage, alfalfa hay, soybean hulls, and a premix of minerals and vitamins. Primiparous animals were $9.00 \pm 1.00$ (mean $\pm \mathrm{SD}$ ) d PP at the time of biopsy and had a BCS of $3.08 \pm 0.30$ and $\mathrm{BW}$ of $618 \pm 74.9 \mathrm{~kg}$. The multiparous animals ( $\geq 3$ parity) were $4.67 \pm 1.15 \mathrm{~d} \mathrm{PP}$ at the time of biopsy and had a BCS of $3.50 \pm 0.65$ and BW of $755 \pm 73.9 \mathrm{~kg}$. Treatments consisted of 3 concentrations of $\left[{ }^{13} \mathrm{C}_{3}\right]$ sodium propionate (99 atom $\%{ }^{13} \mathrm{C}$, Sigma Aldrich, St. Louis, MO) at 1, 2, or $4 \mathrm{mM}$ and sampled at $0.5,15$, and $60 \mathrm{~min}$. The propionate concentrations (PrC) were chosen to bracket the $2.5 \mathrm{~m} M$ propionate concentration used in previous experiments (Donkin and Armentano, 1995; Zhang et al., 2015).

\section{Data Collection and Analysis}

Prior to the liver biopsy, animals were moved to a surgery room at the Michigan State Dairy Cattle Research and Teaching Center. Liver was biopsied before the morning feeding at approximately $0800 \mathrm{~h}$. Cows were blocked from feed for approximately $30 \mathrm{~min}$ before biopsy and 1 cow was biopsied per day. Liver tissue $(\sim 300-400 \mathrm{mg})$ for the experiment was biopsied as described by Kennedy and Allen (2019a). Tissue was rinsed in sterile ice-cold saline to remove excess blood and then placed in ice-cold supplemented Medium 199 (Sigma Aldrich) for immediate transport to the laboratory. Explants were prepared from biopsied tissue as described by Zhang et al. (2015) and were approximately $4 \mathrm{~mm}$ thick and $9 \mathrm{~mm}$ in diameter. Explants were incubated in $2 \mathrm{~mL}$ of Medium 199 supplemented with 1\% BSA (GenDEPOT, Katy, TX), $0.6 \mathrm{mM}$ oleic acid (Sigma Aldrich), $2 \mathrm{~m} M$ sodium L-lactate (Sigma Aldrich), $0.2 \mathrm{mM}$ sodium pyruvate (Sigma Aldrich), $0.5 \mathrm{~m} M$ L-glutamine (Sigma Aldrich), and either 1, 2, or $4 \mathrm{mM}\left[{ }^{13} \mathrm{C}_{3}\right]$ propionate in $20-\mathrm{mL}$ glass scintillation vials (Research Products International, Mt. Prospect, IL). Prior to addition of tissue, the medium was equilibrated to $38^{\circ} \mathrm{C}$. Vials were flushed with $95 \% \quad \mathrm{O}_{2}: 5 \%$ $\mathrm{CO}_{2}$, capped, and then gently agitated at 40 strokes per minute at $38^{\circ} \mathrm{C}$ in a Precision Reciprocal Shaking Bath (Thermo Fisher Scientific, Waltham, MA) until the designated sampling time. Samples were then removed from the medium with sterile tweezers, rapidly blotted $(\sim 10 \mathrm{~s})$ on Kimwipes (Kimtech Science, Kimberly-Clark Professional, Roswell, GA), placed in 2-mL screw-cap tubes with O-ring caps (Thomas Scientific; Swedesboro, NJ), and dropped in liquid nitrogen. Samples were stored at $-80^{\circ} \mathrm{C}$ until analysis. Tissue not used for explants was frozen in liquid nitrogen as 
described and used as a baseline (0 min) and correction factor for the natural abundance of isotopes.

Explants were analyzed for citrate, isocitrate, succinate, fumarate, malate, pyruvate, lactate, glutamate, oxaloacetate (OAA), $\alpha$-ketoglutarate, and glucose by GC-MS and for acetyl CoA and propionyl CoA by liquid chromatography-tandem MS (LC-MS/MS). Samples were prepared for mass spectrometry analysis and analyzed on GC-MS and LC-MS/MS using the methods described by Kennedy and Allen (2019b), except additional $\mathrm{m} / \mathrm{z}$ values were monitored to account for complete ${ }^{13} \mathrm{C}$ tracer incorporation into the metabolites ([M $+\mathrm{n}])$. Samples analyzed on GC-MS were derivatized by methoximation and silylation as described by Kennedy and Allen (2019a). Machine run was defined as the group of samples analyzed on a mass spectrometer within a single session (GC-MS). Area quantification of peaks were integrated using MassLynx Mass Spectrometry Software (version 4.1, Waters Corporation, Milford, MA). Naturally low abundance of isocitrate caused data to be undetectable or unreliable with higher isotopologues, thus the data were not included. Additionally, an unknown mass at $[\mathrm{M}+2]$ for OAA and $\alpha$-ketoglutarate interfered with those isotopologues by masking their abundance, including unlabeled samples, and thus the data were not included. Quantified area was corrected using the recorded weight of each explant (grams of wet weight). Limit of detection was calculated (Armbruster and Pry, 2008) and undetectable values were assigned a value of limit of detection/2 (Hornung and Reed, 1990). Total percent of ${ }^{13} \mathrm{C}$ enrichment of each metabolite was calculated as modified from Wang and Jones (2014) using the following equation:

$$
{ }^{13} \mathrm{C} \% \text { enrichment }=\frac{\left[\left(\bar{M}_{L}-\bar{M}_{U} / 13.00335-12\right) \times 100\right]}{n \text { carbons in metabolite }},
$$

where $\bar{M}_{L}$ is the weighted average isotopologue mass of the labeled metabolite, $\bar{M}_{U}$ is the weighted average isotopologue mass of the unlabeled metabolite, and the denominator is the difference between ${ }^{13} \mathrm{C}$ and ${ }^{12} \mathrm{C}$ atomic masses. Additionally, this equation adjusts for the number of carbons within each metabolite, not including carbons within CoA. This equation is a simple representation of stable isotope labeling and calculates the total percent increase of ${ }^{13} \mathrm{C}$ over its natural abundance that is present within a metabolite (i.e., it does not distinguish between the distribution of isotopologues within the metabolite).

Additionally, the isotope enrichment, expressed as molar percent, was calculated for the isotopologues $[\mathrm{M}+3]$ propionyl $\mathrm{CoA}, \quad[\mathrm{M}+2]$ pyruvate, $[\mathrm{M}+1]$ acetyl
CoA, $[\mathrm{M}+2]$ acetyl $\mathrm{CoA},[\mathrm{M}+3]$ citrate, $[\mathrm{M}+4]$ citrate, $[\mathrm{M}+5]$ citrate, $\quad[\mathrm{M}+2]$ glutamate, $[\mathrm{M}+3]$ glutamate, $[\mathrm{M}+2]$ glucose, and $[\mathrm{M}+3]$ glucose as follows: (1) integrated areas per gram were normalized to $[\mathrm{M}+0]$ as a percentage, (2) they were multiplied by a correction matrix based on the stable isotope distribution of each compound in unlabeled samples (Fernandez et al., 1996), and (3) each isotopologue was divided by the total isotopologue abundance (Wilson et al., 2017). The enrichment of each isotopologue is relative to the mass distribution of all the isotopologues in the metabolite and is on a scale of 0 to $100 \%$. The isotopologues $[\mathrm{M}+2]$ pyruvate, $[\mathrm{M}+1]$ acetyl $\mathrm{CoA},[\mathrm{M}+2]$ acetyl $\mathrm{CoA},[\mathrm{M}+3]$ citrate, $[\mathrm{M}+4]$ citrate, and $[\mathrm{M}+5]$ citrate were examined because they are key points in determining if acetyl CoA was synthesized from propionate and entered the TCA cycle for oxidation. Because of known labeling patterns of labeled propionate (Supplemental Figure S1, https: //doi.org/10.3168/jds.2020-18914; Kelleher, 1986; Previs and Kelley, 2015), an increase in $[M+2]$ pyruvate or $[\mathrm{M}+3]$ pyruvate is expected, which would result in $[\mathrm{M}+1]$ acetyl $\mathrm{CoA}$ or $[\mathrm{M}+2]$ acetyl CoA through the pyruvate dehydrogenase complex. The labeled acetyl CoA will then condense with $[\mathrm{M}+2]$ - or $[\mathrm{M}+3]$ oxaloacetate to produce $[\mathrm{M}+4]-$ or $[\mathrm{M}+5]$ citrate. Because the carbons derived from acetyl CoA are not oxidized during the initial turn of the TCA cycle, unlabeled acetyl CoA will dilute labeled citrate; as such, an enrichment greater than $[\mathrm{M}+3]$ citrate would be unexpected from the anaplerosis of $\left[{ }^{13} \mathrm{C}_{3}\right]$ propionate in ruminants. Therefore, enrichment of $[\mathrm{M}+4]$ citrate or $[\mathrm{M}+5]$ citrate indicates labeled pyruvate entering the TCA cycle via labeled acetyl CoA. All $[\mathrm{M}+\mathrm{n}]$ of glutamate from propionate results from flux of the TCA cycle as the labeling must have derived from $\alpha$-ketoglutarate through glutamate dehydrogenase (Garcia et al., 2015; Zhang et al., 2015).

\section{Statistical Analysis}

All data were analyzed with mixed models (PROC MIXED) and repeated measures using SAS software (version 9.4, SAS Institute Inc., Cary, NC). Total ${ }^{13} \mathrm{C} \%$ enrichment of each metabolite and isotope enrichment of select isotopologues except for CoA compounds (LCMS/MS analysis) were analyzed with the following model:

$$
\begin{gathered}
Y_{i j k l m}=\mu+C_{i}\left(P_{j}, R_{k}\right)+P_{j}+R_{k}+T_{l}+S_{m}+T_{l} S_{m}+T_{l} P_{j}+, \\
T_{l} R_{k}+P_{j} S_{m}+T_{l} S_{m} P_{j}+e_{i j k l m}
\end{gathered}
$$

where $Y_{i j k l m}=$ the response variable; $\mu=$ overall mean; $C_{i}\left(P_{j}, R_{k}\right)=$ random effect of cow $i$ nested within parity 
$j$ and machine run $k ; P_{j}=$ fixed effect of parity $j ; R_{k}=$ fixed effect of machine run $k ; T_{l}=$ fixed effect of $\operatorname{PrC} l$; $S_{m}=$ fixed effect of sampling time $m ; T_{l} S_{m}=$ interaction of $\mathrm{PrC}$ and sampling time; $T_{l} P_{j}=$ interaction of $\operatorname{PrC}$ and parity; $T_{l} R_{k}=$ interaction of $\operatorname{PrC}$ and machine run; $P_{j} S_{m}=$ interaction of parity and sampling time; $T_{l} S_{m} P_{j}=$ interaction of $\operatorname{PrC}$, sampling time, and parity; and $e_{i j k l m}=$ residual. The CoA compounds were analyzed with the same model as above except the effect of machine run was not included in the model as all samples were analyzed within the same machine run.

Time was used in the repeated statement to account for repeated measures and the subject was defined as $\operatorname{PrC}$ by either cow nested within parity by machinerun interaction (GC-MS analyses) or cow nested within parity (LC-MS/MS analysis). The covariance structure was compound symmetry and denominator degrees of freedom were estimated by using the Kenward-Roger option in the MODEL statement. Paired differences were determined using the diff option with a Tukey adjustment in PROC MIXED.

Main effects and interactions were declared significant at $P \leq 0.05$ and tendencies for significant main effects and interactions were declared at $0.05<P \leq$ 0.10. Box-Cox transformation analyses were applied to response variables that violated the assumptions of normality, homogeneity of residuals, or both as a guide for determining the necessary transformations on the data using JMP Pro (version 13.2, SAS Institute Inc.). Data transformed are noted in the tables and figures along with the transformation used for statistical analysis. All transformed data has been back-transformed for interpretation.

\section{RESULTS}

\section{Total ${ }^{13} \mathrm{C} \%$ Enrichment}

All metabolites had highly significant increases in total ${ }^{13} \mathrm{C} \%$ enrichment over time (Figure $1 ; P<0.0001$ ) except for acetyl CoA $(P=0.19)$. An increase in total ${ }^{13} \mathrm{C} \%$ enrichment between baseline and 0.5 min was observed for propionyl CoA, succinate, fumarate, and glucose (Table 1 ; pairwise tests, $P \leq 0.01$ ). No significant $\operatorname{PrC}$ by machine run interactions were detected $(P$ $>0.15)$.

Increased concentrations of $\left[{ }^{13} \mathrm{C}_{3}\right]$ propionate increased total ${ }^{13} \mathrm{C} \%$ enrichment of succinate, fumarate, malate, citrate, glutamate, pyruvate, and lactate over time (Table 2; Figure 1; interaction, $P \leq 0.01$ ). Propionyl CoA tended to differ for a 3 -way interaction of PrC by parity by time (Figure $1 \mathrm{~A} ; P=0.08$ ). However, parity groups did not differ among $\operatorname{PrC}$ at each time point for pro- pionyl CoA. Propionyl CoA also significantly increased over time with increased concentrations of $\left[{ }^{13} \mathrm{C}_{3}\right]$ propionate $(P<0.01)$. Total ${ }^{13} \mathrm{C} \%$ enrichment of propionyl CoA was increased for the $4 \mathrm{~m} M \operatorname{PrC}$ compared with the $1 \mathrm{~m} M$ and $2 \mathrm{~m} M \operatorname{PrC}$ at $0.5 \min (1 \mathrm{~m} M: 17.4 \%, 2$ $\mathrm{m} M: 23.2 \%, 4 \mathrm{~m} M: 33.8 \%$ enrichment; pairwise tests, $P \leq 0.05)$, but we detected no difference between the 1 and $2 \mathrm{mM} \operatorname{PrC}$ at $0.5 \mathrm{~min}$ (pairwise tests, $P=0.74$ ). Additionally, total ${ }^{13} \mathrm{C} \%$ enrichment of propionyl $\mathrm{CoA}$ was increased for 2 and $4 \mathrm{~m} M \operatorname{PrC}$ compared with 1 $\mathrm{m} M \operatorname{PrC}$ at 15 (1 $\mathrm{m} M: 35.2 \%, 2 \mathrm{~m} M: 47.8 \%, 4 \mathrm{~m} M$ : $50.7 \%$ enrichment) and $60 \mathrm{~min}(1 \mathrm{~m} M: 51.3 \%, 2 \mathrm{mM}$ : $62.5 \%, 4 \mathrm{~m} M: 65.0 \%$ enrichment; pairwise tests, $P \leq$ $0.03)$, but we detected no difference between the 2 and $4 \mathrm{mM} \operatorname{PrC}$ at 15 and $60 \mathrm{~min}$ (pairwise tests, $P=1.00$ ).

The PrC tended to interact with parity for total ${ }^{13} \mathrm{C} \%$ enrichment of glucose $(P=0.08)$ and citrate $(P$ $=0.09)$; however, no differences were detected between parities at each $\operatorname{PrC}$ (pairwise tests, $P>0.10$ ). Multiparous cows had increased total ${ }^{13} \mathrm{C} \%$ enrichment of citrate with the $2 \mathrm{mM}$ and $4 \mathrm{~m} M \operatorname{PrC}$ compared with $1 \mathrm{~m} M \operatorname{PrC}(1 \mathrm{~m} M: 3.97 \%$ vs. $2 \mathrm{~m} M: 5.41 \%$ or $4 \mathrm{~m} M$ : $6.00 \%$ enrichment; pairwise tests, $P \leq 0.01$ ). Primiparous cows also had increased total ${ }^{13} \mathrm{C} \%$ enrichment of citrate with the $2 \mathrm{mM}$ and $4 \mathrm{~m} M \operatorname{PrC}$ compared with $1 \mathrm{~m} M \operatorname{PrC}(1 \mathrm{~m} M: 3.62 \%$ vs. $2 \mathrm{~m} M: 4.41 \%$ or $4 \mathrm{~m} M$ : $4.86 \%$ enrichment; pairwise tests, $P<0.05)$. The $\operatorname{PrC}$ concentrations did not differ within multiparous or primiparous cows for total ${ }^{13} \mathrm{C} \%$ enrichment of glucose $(P>0.35)$.

Concentration of $\left[{ }^{13} \mathrm{C}_{3}\right]$ propionate had no effect on total ${ }^{13} \mathrm{C} \%$ enrichment of glutamate, glucose or acetyl CoA (Table $2 ; P>0.15$ ). We detected a main effect $(P \leq 0.01)$ for $\left[{ }^{13} \mathrm{C}_{3}\right]$ propionate concentration on total ${ }^{13} \mathrm{C} \%$ enrichment of propionyl $\mathrm{CoA}$, succinate, fumarate, malate, citrate, pyruvate, and lactate.

\section{${ }^{13} \mathrm{C} \%$ Enrichment of Isotopologues}

All isotopologues increased in ${ }^{13} \mathrm{C} \%$ enrichment over time (Table 3; Figure 2; $P<0.0001$ ) except for $[\mathrm{M}+1]$ and $[\mathrm{M}+2]$ acetyl CoA $(P>0.50)$. A tendency for a $\operatorname{PrC}$ by machine run interaction was detected for $[\mathrm{M}+2]$ pyruvate $(P=0.09)$; however, no differences were detected between machine runs within $\operatorname{PrC}$ (pairwise tests, $P>0.35)$.

Effect of different concentrations of $\left[{ }^{13} \mathrm{C}_{3}\right]$ propionate on ${ }^{13} \mathrm{C} \%$ enrichment of isotopologues are shown in Table 3. The ${ }^{13} \mathrm{C} \%$ enrichment of $[\mathrm{M}+2]$ pyruvate, $[\mathrm{M}+1]$ acetyl CoA, $[\mathrm{M}+3]$ citrate, $[\mathrm{M}+4]$ citrate, $[\mathrm{M}+5]$ citrate, and $[\mathrm{M}+3]$ glutamate had significant $\operatorname{PrC}$ by time interactions (Figure 2; $P \leq 0.05$ ), and $[\mathrm{M}+2]$ glutamate had a tendency for a PrC by time interaction $(P=$ 


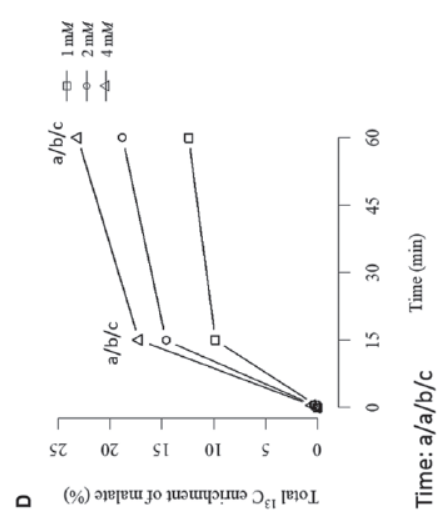

首算首

$\phi \phi \phi$

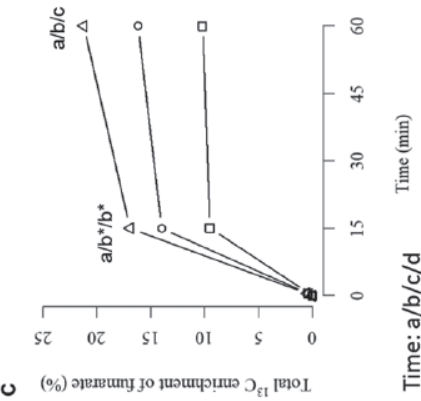

首算首

中 $\phi$

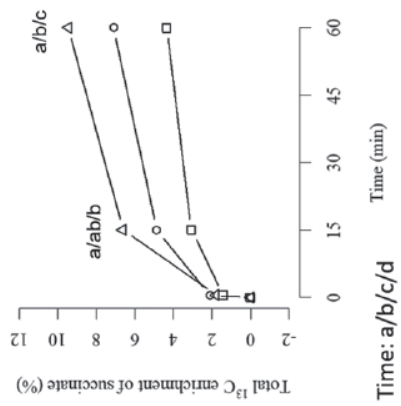

$\infty$

\section{首算算算首

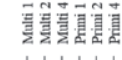
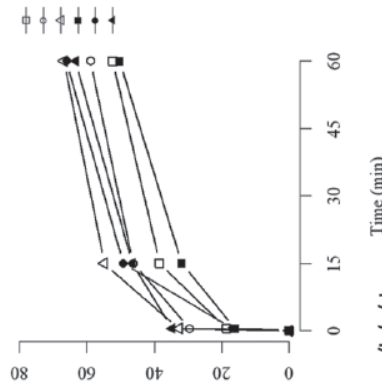

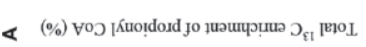

首算首

$\phi \phi \phi$

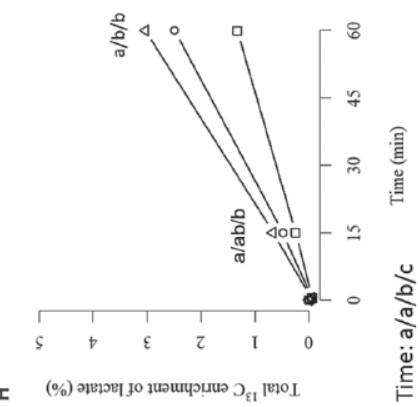

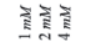
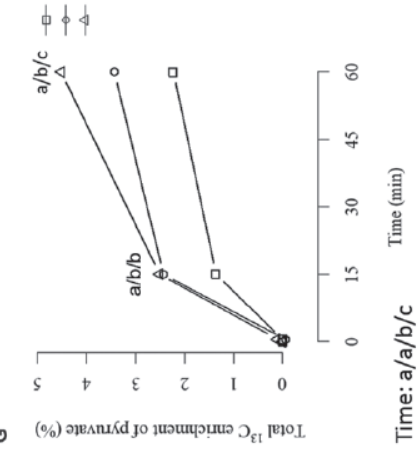

首解道

$\phi \phi \phi$

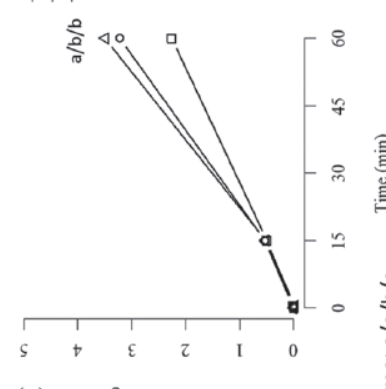

4

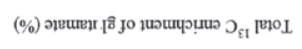

\section{首算首}

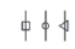

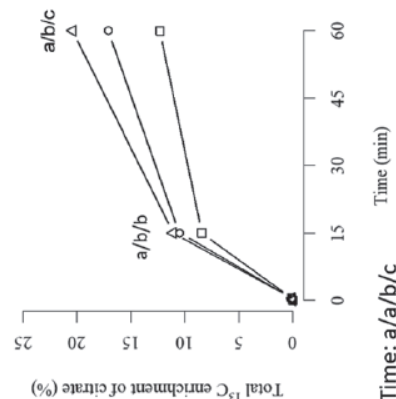

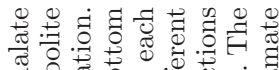

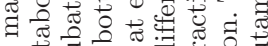
Oि.

궁

政

.

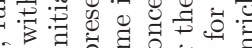

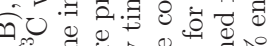

等

然

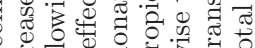

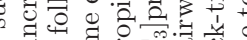

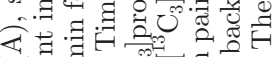

䜦

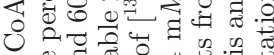

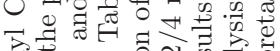

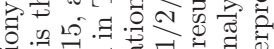

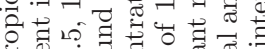

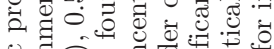

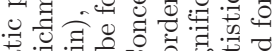

空

过

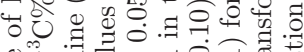

O

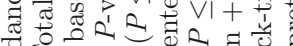

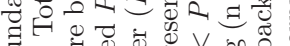

言.

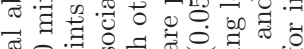

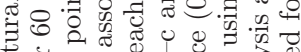

㟧

है욜

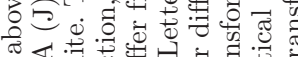

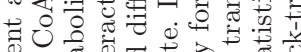

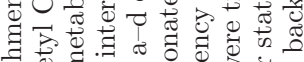

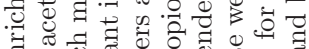

व

०

Of

ส

过势元

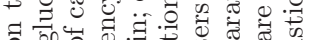

00 o

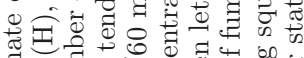

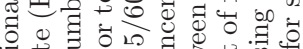

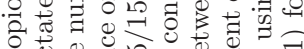

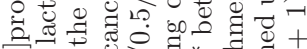

$0^{\circ} \overline{0}$

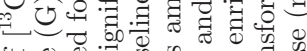

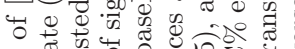

a

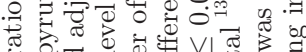

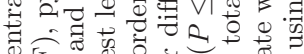

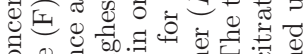

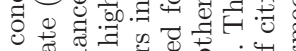

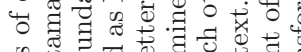

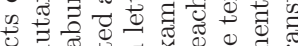

政

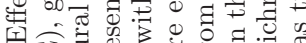

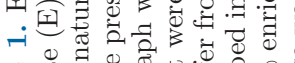

o

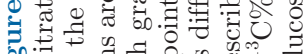

bo 넝 0

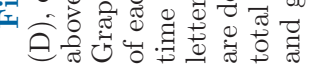


Table 1. Difference of total ${ }^{13} \mathrm{C} \%$ enrichment above natural abundance of select hepatic metabolites with significant sampling time effect (Table 2; $P<0.0001$ ), assuming $0 \%$ total ${ }^{13} \mathrm{C}$ enrichment (baseline, $0 \mathrm{~min}$ ) and after incubation of explant for approximately $0.5 \mathrm{~min}$ in $\left[{ }^{13} \mathrm{C}_{3}\right]$ propionate

\begin{tabular}{lccc}
\hline Metabolite $^{1}$ & $0 \mathrm{~min}$ & $0.5 \mathrm{~min}$ & $P$-value \\
\hline Propionyl CoA & $0.00^{(-2.50,2.50)}$ & $24.8^{(22.3,27.3)}$ & $<0.0001$ \\
Succinate & $0.00^{(-0.62,0.62)}$ & $1.77^{(1.15,2.39)}$ & $<0.01$ \\
Fumarate $^{3}$ & $0.00^{(-0.05,0.06)}$ & $0.45^{(0.37,0.53)}$ & $<0.0001$ \\
Malate & $0.00^{(-0.79,0.79)}$ & $0.38^{(-0.42,1.17)}$ & 0.76 \\
Citrate $^{4}$ & $0.00^{(-0.17,0.18)}$ & $0.09^{(-0.08,0.28)}$ & 0.76 \\
Glutamate $^{5}$ & $0.00^{(-0.02,0.02)}$ & $0.00^{(-0.01,0.02)}$ & 0.99 \\
Pyruvate $_{\text {Lactate }^{3}}$ & $0.00^{(-0.26,0.26)}$ & $0.02^{(-0.24,0.28)}$ & 1.00 \\
Glucose $^{5}$ & $0.00^{(-0.06,0.07)}$ & $-0.06^{(-0.12,0.01)}$ & 0.29 \\
\hline
\end{tabular}

${ }^{1}$ Total percent of ${ }^{13} \mathrm{C}$ enrichment above natural abundance adjusted for number of carbons in each metabolite. Values reported as $\operatorname{LSM}^{(95 \% \mathrm{CI})}$. ${ }^{2}$ Pairwise comparisons were adjusted with Tukey's method.

${ }^{3}$ Data transformed using $\log (\mathrm{n}+1)$ for statistical analysis and backtransformed for interpretation.

${ }^{4}$ Data transformed using square root $(\mathrm{n}+1)$ for statistical analysis and back-transformed for interpretation.

${ }^{5}$ Data transformed using inverse $(\mathrm{n}+1)$ for statistical analysis and back-transformed for interpretation.

0.08). The ${ }^{13} \mathrm{C} \%$ enrichment of $[\mathrm{M}+3]$ citrate tended to be greater with the $4 \mathrm{mM}$ than $2 \mathrm{mM} \mathrm{PrC}$ at $60 \mathrm{~min}$ (pairwise test, $P=0.06$ ). Additionally, ${ }^{13} \mathrm{C} \%$ enrichment of $[\mathrm{M}+2]$ glutamate tended to be greater with the $2 \mathrm{~m} M$ than $1 \mathrm{~m} M \operatorname{PrC}$ at $60 \mathrm{~min}$ (pairwise test, $P=$ $0.10)$, and ${ }^{13} \mathrm{C} \%$ enrichment of $[\mathrm{M}+3]$ glutamate tended to be greater with the $4 \mathrm{~m} M$ than $1 \mathrm{~m} M \operatorname{PrC}$ at 60 min (pairwise test, $P=0.06$ ). The $\operatorname{PrC}$, time, and parity tended to interact for ${ }^{13} \mathrm{C} \%$ enrichment of $[\mathrm{M}+3]$ propionyl CoA (Figure 2A; $P=0.10$ ); however, parity did not differ among $\mathrm{PrC}$ at each time point for $[\mathrm{M}+3]$ propionyl CoA.

The $\mathrm{PrC}$ interacted with parity for ${ }^{13} \mathrm{C} \%$ enrichment of $[\mathrm{M}+2]$ pyruvate, $[\mathrm{M}+2]$ glucose, and $[\mathrm{M}+3]$ glucose $(P$ $<0.05$, ) and $\operatorname{PrC}$ tended to interact with parity for ${ }^{13} \mathrm{C} \%$ enrichment of $[\mathrm{M}+3]$ citrate $(P=0.10$; Figure 3). Differences among $\operatorname{PrC}$ within parity are shown in Figure 3 . The ${ }^{13} \mathrm{C} \%$ enrichment of $[\mathrm{M}+2]$ pyruvate and $[\mathrm{M}+3]$ glucose was greater for multiparous cows than primiparous cows with the $2 \mathrm{~m} M \operatorname{PrC}(2.54 \%$ vs. $1.75 \%$ and $0.16 \%$ vs. $0.07 \%$, respectively; pairwise tests, $P \leq$ $0.05)$. Additionally, $[\mathrm{M}+3]$ glucose was greater for multiparous cows than primiparous cows with the $4 \mathrm{mM}$ $\operatorname{PrC}(0.16 \%$ vs. $0.08 \%$; pairwise test, $P=0.05)$, and $[\mathrm{M}+3]$ citrate tended to be greater for multiparous cows than primiparous cows with the $4 \mathrm{~m} M \operatorname{PrC}(12.6 \%$ vs. $10.0 \%$; pairwise test, $P=0.07)$. The ${ }^{13} \mathrm{C} \%$ enrichment of $[\mathrm{M}+2]$ glucose did not differ between parity within each $\mathrm{PrC}$ (pairwise tests, $P>0.10$ ).

\section{DISCUSSION}

Total ${ }^{13} \mathrm{C} \%$ enrichment of acetyl CoA did not increase with increased concentrations of $\left[{ }^{13} \mathrm{C}_{3}\right]$ propionate, nor did ${ }^{13} \mathrm{C} \%$ enrichment of acetyl $\mathrm{CoA}$ increase over time compared with the baseline. Although no significant $\mathrm{PrC}$ or time effects were detected for [M+2] acetyl CoA enrichment, $[\mathrm{M}+4]$ citrate and $[\mathrm{M}+5]$ citrate enrichment significantly increased over time and with increased PrC. Significant $[M+3]$ citrate enrichment would be ex-

Table 2. Effects of 3 different concentrations of $\left[{ }^{13} \mathrm{C}_{3}\right]$ propionate $(1,2$, or $4 \mathrm{mM})$ on total ${ }^{13} \mathrm{C} \%$ enrichment of select hepatic metabolites over $60 \mathrm{~min}$

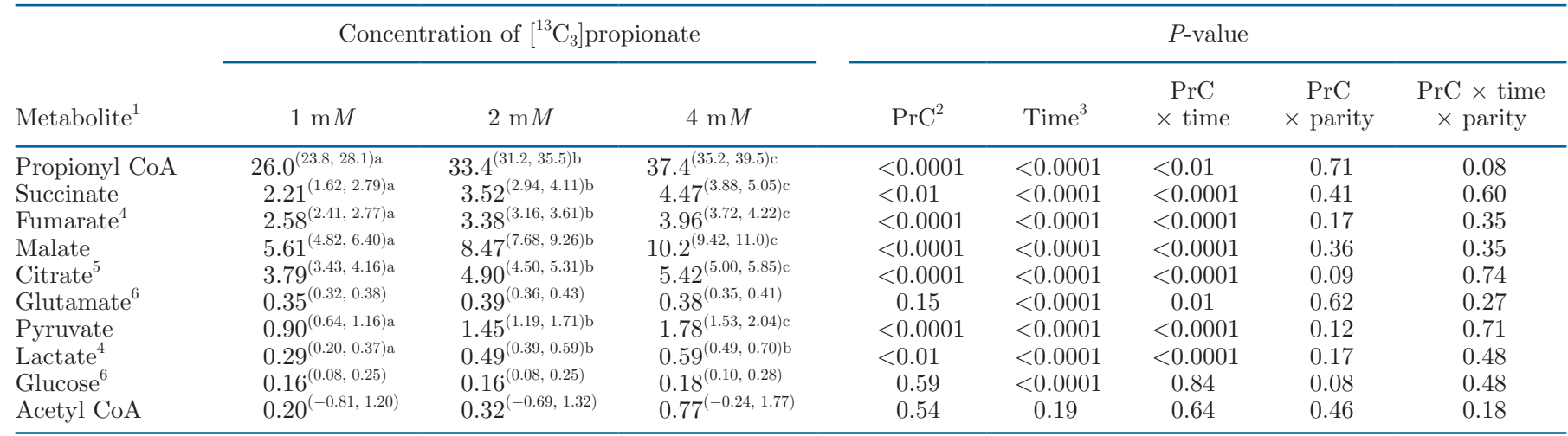

\footnotetext{
${ }^{\mathrm{a}-\mathrm{c}}$ Means within a row with different superscripts differ $(P \leq 0.05)$.

${ }^{1}$ Total percent of ${ }^{13} \mathrm{C}$ enrichment above natural abundance adjusted for number of carbons in each metabolite. Values reported as LSM $\left.{ }^{(95 \%} \mathrm{CI}\right)$.

${ }^{2} \mathrm{PrC}=$ concentration of $\left[{ }^{13} \mathrm{C}_{3}\right]$ propionate.

${ }^{3}$ Time $=$ sampling time; sampling time points are baseline, $0.5,15$, and $60 \mathrm{~min}$.

${ }^{4}$ Data transformed using $\log (\mathrm{n}+1)$ for statistical analysis and back-transformed for interpretation.

${ }^{5}$ Data transformed using square root $(n+1)$ for statistical analysis and back-transformed for interpretation.

${ }^{6}$ Data transformed using inverse $(n+1)$ for statistical analysis and back-transformed for interpretation.
} 
Table 3. Effects of 3 different concentrations of $\left[{ }^{13} \mathrm{C}_{3}\right]$ propionate $(1,2$, or $4 \mathrm{mM})$ on ${ }^{13} \mathrm{C} \%$ enrichment of select hepatic metabolite isotopologues over $60 \mathrm{~min}$

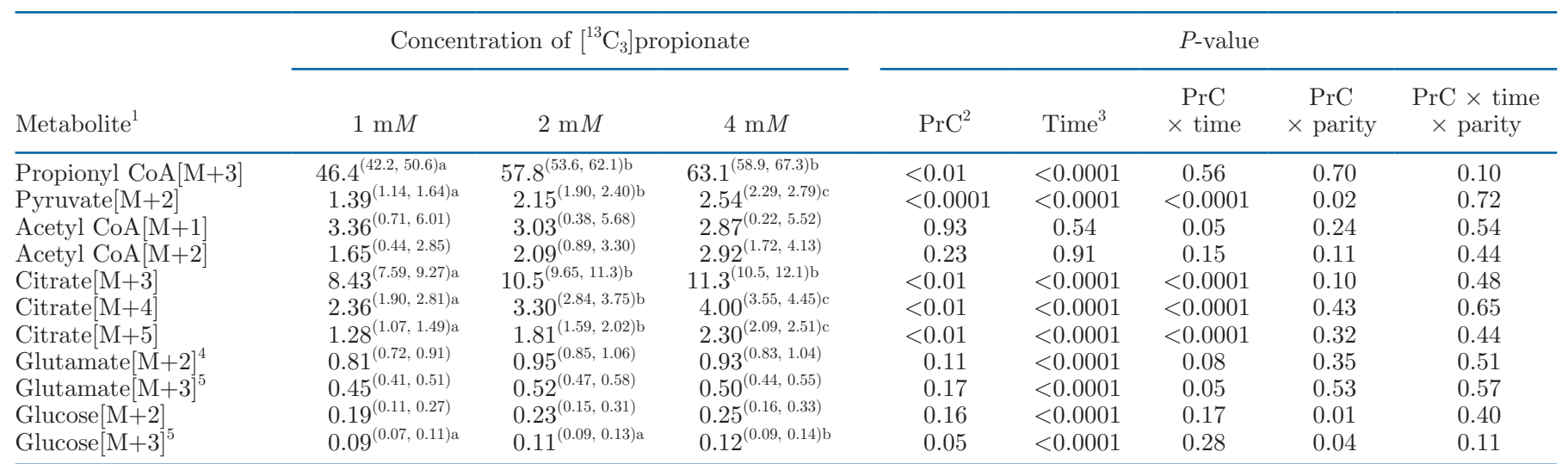

${ }^{\mathrm{a}-\mathrm{c}}$ Means within a row with different superscripts differ $(P \leq 0.05)$.

${ }^{1}$ Enrichment of each isotopologue is relative to the mass distribution of all the isotopologues in the metabolite (molar percent) and is on a scale of 0 to $100 \%$. Values reported as $\operatorname{LSM}^{(95 \% \mathrm{CI})}$.

${ }^{2} \mathrm{PrC}=$ concentration of $\left[{ }^{13} \mathrm{C}_{3}\right]$ propionate.

${ }^{3}$ Time $=$ sampling time; sampling time points are $0.5,15$, and $60 \mathrm{~min}$.

${ }^{4}$ Data transformed using inverse square root $(n+1)$ for statistical analysis and back-transformed for interpretation.

${ }^{5}$ Data transformed using inverse $(n+1)$ for statistical analysis and back-transformed for interpretation.

pected as $\left[{ }^{13} \mathrm{C}_{3}\right]$ propionate feeds into the TCA cycle, but labeling beyond $[\mathrm{M}+3]$ citrate requires labeled acetyl CoA. Enrichment of pyruvate and $[M+2]$ pyruvate significantly increased with $\mathrm{PrC}$ over time, indicating that propionate was converted to pyruvate. Because ATP citrate lyase and malic enzyme are negligible in the liver of ruminants (Hanson and Ballard, 1967; Young et al., 1969), the labeled acetyl CoA is likely derived from labeled pyruvate. However, the pyruvate dehydrogenase complex is tightly regulated (Williamson and Cooper, 1980) and the rate of synthesis of acetyl CoA was not likely affected by the concentration of pyruvate because pyruvate carboxylase is upregulated during this stage of lactation (Greenfield et al., 2000). Therefore, the tight regulation of the pyruvate dehydrogenase complex could partially explain the lack of $\operatorname{PrC}$ effect detected for enrichment of acetyl CoA when incubated with a concentration of propionate from 1 to $4 \mathrm{~m} M$. However, dilution from naturally high concentrations of hepatic acetyl CoA in dairy cows in the PP period (Piantoni et al., 2015) due to lipolysis likely contributed to detecting minimal enrichment of ${ }^{13} \mathrm{C}$-labeled acetyl $\mathrm{CoA}$ as well. Contrary to Greenfield et al. (2000), Garcia et al. (2015) reported an increase in the relative activity of the pyruvate dehydrogenase complex versus pyruvate carboxylase when liver slices from early-lactation cows were incubated with a pyruvate and propionate treatment compared with a pyruvate only treatment for $2 \mathrm{~h}$. Notably, Garcia et al. (2015) did not measure enrichment of acetyl CoA directly, but estimated [M+2]acetyl
CoA enrichment from glutamate enrichment. Although pyruvate carboxylase may incorporate some ${ }^{13} \mathrm{CO}_{2}$ for the conversion of pyruvate to OAA, this contribution is likely negligible. Additionally, this incorporation would not result in $[\mathrm{M}+5]$ citrate, of which we detected differences among PrC.

In addition to its anaplerotic capabilities, propionate is a primary glucose precursor in dairy cows. Estimates of propionate contribution to glucose synthesis range from 61 to 95\% (Wiltrout and Satter, 1972; Armentano, 1992). However, enrichment of intracellular hepatic glucose was approximately $0.5 \%$ when adjusted to a per carbon basis at its greatest enrichment, and no $\mathrm{PrC}$ nor $\mathrm{PrC}$ by time effects were detected. Similar to total ${ }^{13} \mathrm{C} \%$ enrichment of glucose, $[\mathrm{M}+3]$ glucose enrichment increased over time, but enrichment did not exceed $1 \%$. However, $[\mathrm{M}+3]$ glucose enrichment was higher in multiparous than primiparous animals at higher $\left[{ }^{13} \mathrm{C}_{3}\right]$ propionate concentrations. Notably, we measured the ${ }^{13} \mathrm{C}$ enrichment of the accumulated, free glucose located within the hepatic tissue and not the extracellular labeling of glucose, but free glucose is released from hepatic tissue for use by other tissues. Any glucose that is retained within cells is stored as glycogen, approximately $8 \%$ on a DM basis for dairy cows 7 to 14 DIM (Vazquez-Añon et al., 1994), but we did not measure glycogen in this experiment. Furthermore, the enzymes glucokinase and hexokinase (EC 2.7.1.2 and EC 2.7.1.1, respectively) are minimal in the liver of dairy cows (Ballard, 1965), and as such, recycling and 
首尊首

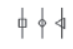

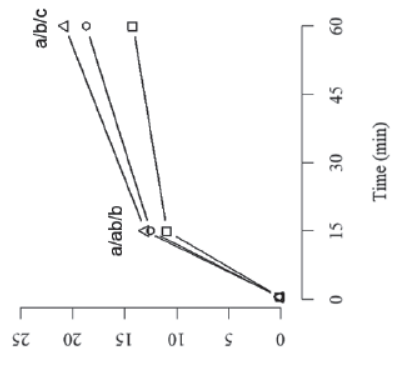

口

\section{首算}

,

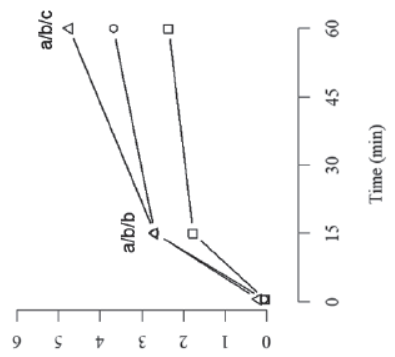

○

\section{首着}

中中

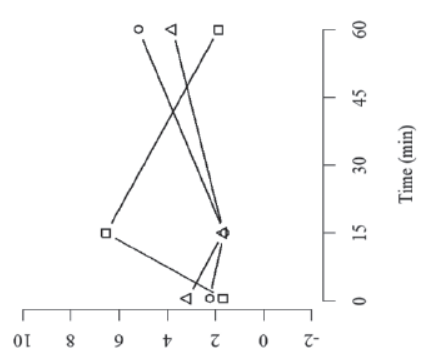

$\infty$

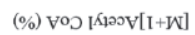
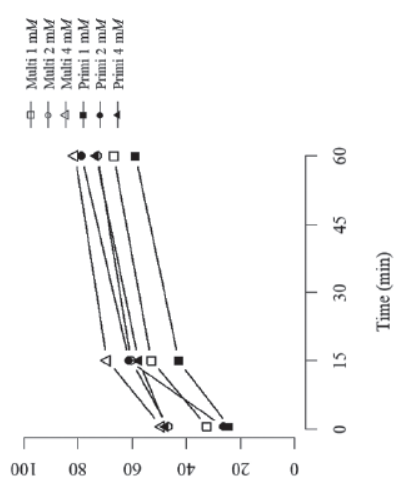

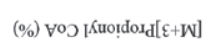

筫首

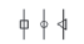

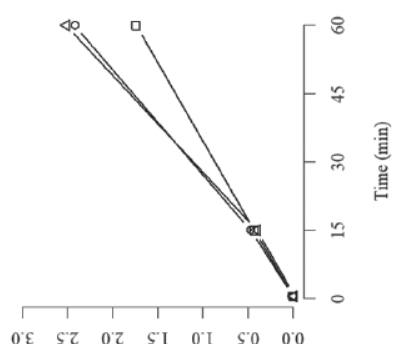

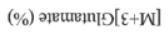

\section{算章}

中 $\phi$

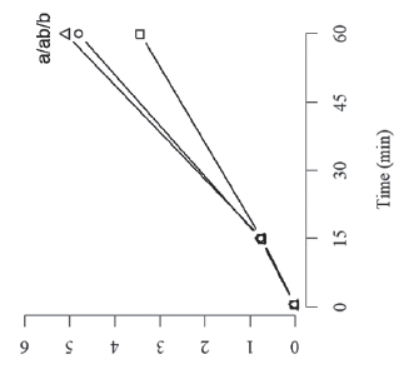

0

\section{首首首}

$\phi \phi \phi$

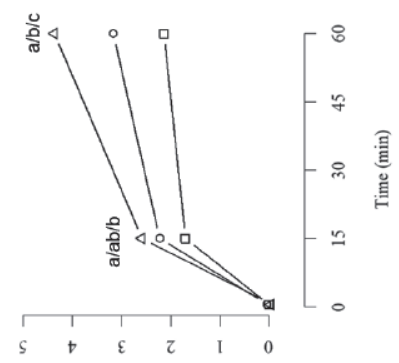

$\leftarrow$

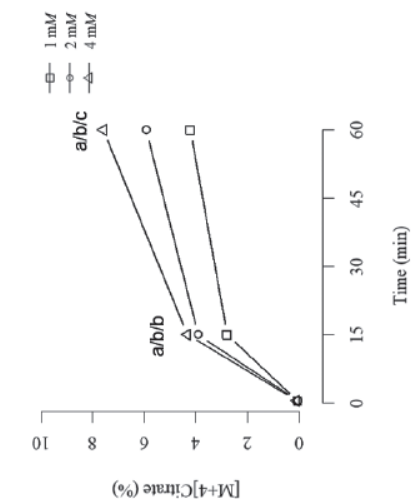

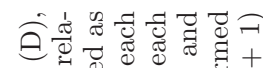

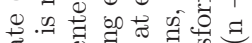

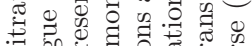

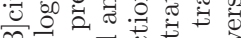

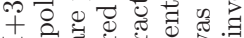

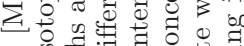

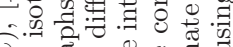

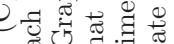

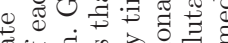

पै

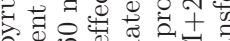

घ

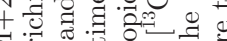

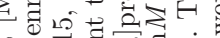

ติ

$\varangle 0000 \mathrm{~N}$

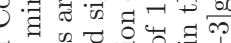

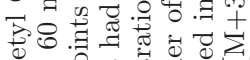

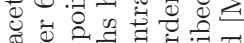

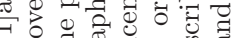

$+\curvearrowright$.

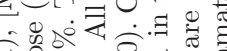

\

-

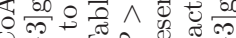

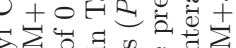

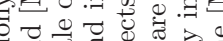

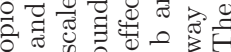

हैं

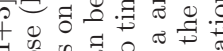

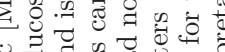

咭范

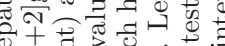

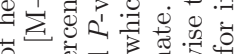

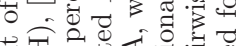

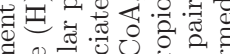

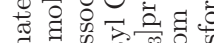

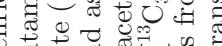

击清

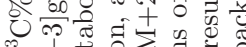

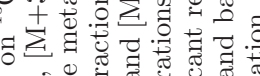

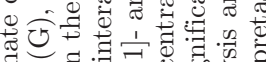

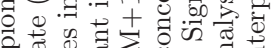

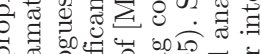

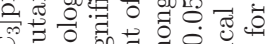

क人 o.

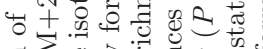

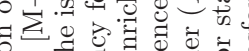

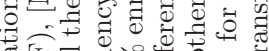

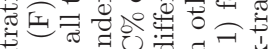

잉

ब

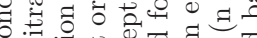

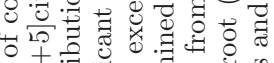

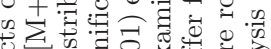

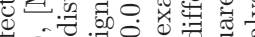

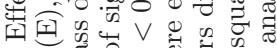

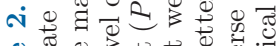

0.

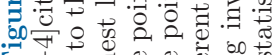

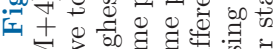


A
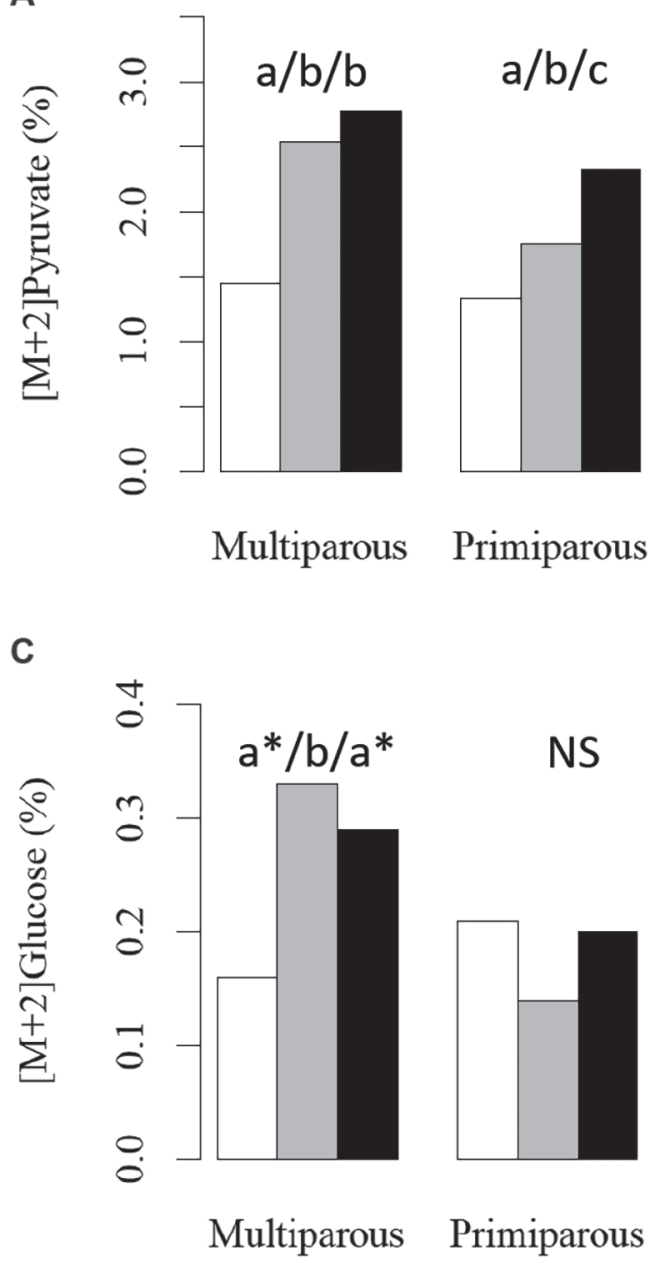

B
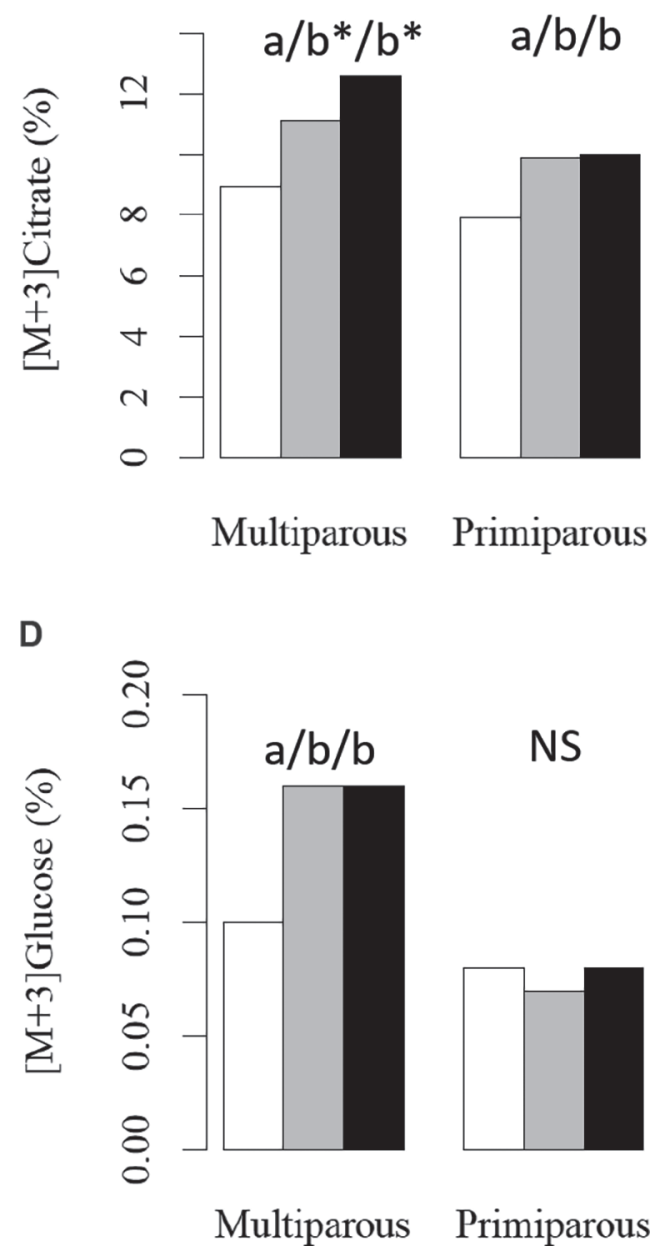

Figure 3. The effect of parity and concentration of $\left[{ }^{13} \mathrm{C}_{3}\right]$ propionate on ${ }^{13} \mathrm{C} \%$ enrichment of hepatic $[\mathrm{M}+2]$ pyruvate $(\mathrm{A})$, [M+3]citrate $(\mathrm{B})$, $[\mathrm{M}+2]$ glucose $(\mathrm{C})$, and $[\mathrm{M}+3]$ glucose $(\mathrm{D})$. The enrichment of each isotopologue is relative to the mass distribution of all the isotopologues in the metabolite (molar percent) and is on a scale of 0 to $100 \%$. Letters a-c are presented in the order of $1 / 2 / 4 \mathrm{~m} M\left[{ }^{13} \mathrm{C}_{3}\right]$ propionate concentrations; different letters differ from each other $(P \leq 0.05)$, and $*$ between letters signifies a tendency for difference $(0.05<P \leq 0.10)$. The $[\mathrm{M}+3]$ glucose was transformed using inverse $(n+1)$ for statistical analysis and back-transformed for interpretation.

absorption of extracellular glucose is likely negligible as well. Consequently, we suspect that because extracellular glucose represents a sink for $\left[{ }^{13} \mathrm{C}\right]$ propionate, we were unable to observe changes in glucose enrichment. Additionally, the detected enrichment of $\left[{ }^{13} \mathrm{C}\right]$ glucose is likely an artifact of the accumulated residual glucose in the medium, which is likely very diluted due to the $\left[{ }^{12} \mathrm{C}\right]$ glucose initially present in the medium. Therefore, the appearance of the isotope in the intracellular pool does not likely reflect the labeling of glucose, nor can this be determined from analysis of the medium due to the initial presence of $\left[{ }^{12} \mathrm{C}\right]$ glucose in the medium that would assuredly dilute isotope enrichment.

Although propionate is the primary glucose precursor in dairy cows, its contribution slightly decreases in the immediate PP period (approximately 60\%), despite increased propionate uptake and glucose output. Lactate, also a gluconeogenic precursor, contributes approximately $25 \%$ to glucose synthesis during the PP period (Aschenbach et al., 2010). Because lactate was present in our medium, glucose synthesis from lactate may have also diluted the observed enrichment of free glucose from propionate. Additionally, extracellular $\left.{ }^{12} \mathrm{C}\right]$ lactate from the medium also likely diluted the detected accumulation of ${ }^{13} \mathrm{C}$ enriched lactate to some extent.

Our PrC were chosen to bracket the $2.5 \mathrm{~m} M$ propionate concentration used in previous experiments, which suggest that a concentration of $2.5 \mathrm{mM}$ of propionate for a 2-h incubation supplies enough propionate for a 
steady state to be achieved (Donkin and Armentano, 1995; Zhang et al., 2015). Although our lowest PrC was $1 \mathrm{mM}\left[{ }^{13} \mathrm{C}_{3}\right]$ propionate, Reynolds et al. (2003) stated that $795 \mathrm{mmol} / \mathrm{h}$ of propionate was measured from net portal-drained viscera, and that plasma flow through the portal vein was $1,287 \mathrm{~L} / \mathrm{h}$ for dairy cows 11 -d PP on a $24 \%$ starch diet. Therefore, a mean of approximately $0.62 \mathrm{~m} M$ plasma propionate was present in the portal vein for those dairy cows. A similar concentration (0.44 $\mathrm{m} M$ ) was reported by Bergman et al. (1966) for sheep consuming a full ration and infused with $\sim 25 \mathrm{mmol} / \mathrm{h}$ of propionic acid into the rumen vein. Whereas both of these circulating concentrations are below our lowest $\operatorname{PrC}$ concentration $(1 \mathrm{mM})$, they are mean concentrations over hours and ruminal production and portaldrained viscera flux of propionate is highly variable over time relative to meals (Benson et al., 2002). Also, hepatocytes might have greater capacity for propionate metabolism beyond physiological levels as suggested by Armentano (1992).

Enrichment of metabolites increased as concentration of $\left[{ }^{13} \mathrm{C}_{3}\right]$ propionate increased for the majority of measured metabolites from 1 to $4 \mathrm{~m} M$, which suggests an increase in anaplerosis at higher concentrations of $\left[{ }^{13} \mathrm{C}_{3}\right]$ propionate in the range of 1 to $4 \mathrm{mM}$. The observed increase in enrichment of glutamate over time supports increased anaplerosis by propionate and suggests that $\alpha$-ketoglutarate was enriched as well because glutamate can be synthesized from $\alpha$-ketoglutarate via the glutamate dehydrogenase reaction (EC 1.4.1.2). This reaction oxidizes $\mathrm{NADH}$ to $\mathrm{NAD}^{+}$, which in turn replenishes the supply of $\mathrm{NAD}^{+}$that is used as a cofactor in many reactions within and associated with the TCA cycle. Additionally, increased enrichment of glutamate over time supports that the explants were alive and continuing to properly function metabolically throughout our experiment.

Enrichment of metabolites associated with propionate metabolism increased with time as expected, and significant detection of enrichment was present for all metabolites except acetyl CoA by 15 min. In our experiment, we were interested in the short-term effects of propionate metabolism and effect of different concentrations of propionate on its metabolism. Furthermore, we chose to use explants for this experiment, which enabled us to provide a similar physiological situation seen in an adult dairy cow in the PP period. However, explants have a shorter life span compared with cell cultures or other in vitro techniques, which informed our choice of time points. Interestingly, ${ }^{13} \mathrm{C}$ enrichment of some metabolites appeared to occur soon after introduction of explants to the incubation medium, as propionyl CoA, succinate, fumarate, and glucose had significant increases in total ${ }^{13} \mathrm{C} \%$ enrichment between baseline and exposure to $\left[{ }^{13} \mathrm{C}_{3}\right]$ propionate-enriched medium for $\sim 0.5 \mathrm{~min}$, independent of $\left[{ }^{13} \mathrm{C}_{3}\right]$ propionate concentration. The 0.5 -min samples were originally proposed as baseline samples. They were taken by adding an explant to medium treated with either 1, 2, or $4 \mathrm{~m} M$ $\left[{ }^{13} \mathrm{C}_{3}\right]$ propionate and then immediately removing the tissue from the medium, blotting it, and then freezing it in liquid nitrogen as previously described. However, rapid incorporation of the stable tracer was observed for some of the measured metabolites; therefore, these samples were unsuitable as baseline values. This rapid incorporation of labeling indicated a near instantaneously labeled pool (within $5 \mathrm{~min}$ ). Additionally, a quasi-steady state was reached for some metabolites by $15 \mathrm{~min}$, such as fumarate.

Propionate is a major volatile fatty acid produced by the rumen of dairy cows and a major glucose precursor, yet research suggests it can decrease DMI, especially during the transition period (Allen and Piantoni, 2013). Dry matter intake is a function of the size and frequency of meals, and adequate DMI is important for transition cow success. Metabolic reactions proceed quickly (within minutes) and dynamic changes occur within a system when studied on a minute time scale that can affect meal size. Therefore, by understanding the short-term metabolism of nutrients, we can begin to imagine new ideas and strategies to improve and manage nutrition in dairy cows to minimize the metabolic stress associated with transition to lactation. Further research is needed to understand the extent of and scenarios in which propionate contributes to oxidation through acetyl CoA production both in in vitro and in vivo models.

\section{CONCLUSIONS}

Despite high concentrations of hepatic acetyl CoA in dairy cows in the PP period, our results indicated that propionate converts to acetyl $\mathrm{CoA}$ and enters the TCA cycle for oxidation; however, propionate does not appreciably accumulate as acetyl CoA, likely due to a rapid turnover rate. Furthermore, the contribution of propionate to oxidation via acetyl $\mathrm{CoA}$ increases as concentrations of propionate increase within a 1 to 4 $\mathrm{m} M$ range as evidenced by an increase in citrate.

\section{ACKNOWLEDGMENTS}

This work is supported by AFRI NIFA Fellowships Grant Program (2017-67011-26042 / 1010850) from the USDA National Institute of Food and Agriculture (Washington, DC). We also thank H. Brunengraber 
(Case Western Reserve University, Cleveland, OH), D. G. Main, R. Albornoz, G. Maldini, A. Meade and R. West (all from Michigan State University, East Lansing), as well as the staff of the Michigan State University Dairy Cattle Field Laboratory (East Lansing) and Michigan State University Mass Spectrometry and Metabolomics Core (East Lansing) for their assistance in this experiment. The authors have not stated any conflicts of interest.

\section{REFERENCES}

Aiello, R. J., and L. E. Armentano. 1987. Effects of volatile fatty acids on propionate metabolism and gluconeogenesis in caprine hepatocytes. J. Dairy Sci. 70:2504-2510. https://doi.org/10.3168/jds .S0022-0302(87)80318-1.

Aiello, R. J., L. E. Armentano, S. J. Bertics, and A. T. Murphy. 1989. Volatile fatty acid uptake and propionate metabolism in ruminant hepatocytes. J. Dairy Sci. 72:942-949. https://doi.org/10.3168/jds S0022-0302(89)79187-6.

Allen, M. S. 2000. Effects of diet on short-term regulation of feed intake by lactating dairy cattle. J. Dairy Sci. 83:1598-1624. https:// doi.org/10.3168/jds.S0022-0302(00)75030-2.

Allen, M. S., and P. Piantoni. 2013. Metabolic control of feed intake: Implications for metabolic disease of fresh cows. Vet. Clin. North Am. Food Anim. Pract. 29:279-297. https://doi.org/10.1016/j .cvfa.2013.04.001.

Armbruster, D. A., and T. Pry. 2008. Limit of blank, limit of detection and limit of quantitation. Clin. Biochem. Rev. 29:S49-S52.

Armentano, L. E. 1992. Ruminant hepatic metabolism of volatile fatty acids, lactate and pyruvate. J. Nutr. 122(suppl_3):838-842. https: //doi.org/10.1093/jn/122.suppl_3.838.

Aschenbach, J. R., N. B. Kristensen, S. S. Donkin, H. M. Hammon, and G. B. Penner. 2010. Gluconeogenesis in dairy cows: The secret of making sweet milk from sour dough. IUBMB Life 62:869-877. https://doi.org/10.1002/iub.400.

Ballard, F. J. 1965. Glucose utilization in mammalian liver. Comp. Biochem. Physiol. 14:437-443. https://doi.org/10.1016/0010 -406X(65)90218-5.

Bauman, D. E., and W. B. Currie. 1980. Partitioning of nutrients during pregnancy and lactation: A review of mechanisms involving homeostasis and homeorhesis. J. Dairy Sci. 63:1514-1529. https:// doi.org/10.3168/jds.S0022-0302(80)83111-0.

Benson, J. A., C. K. Reynolds, P. C. Aikman, B. Lupoli, and D. E. Beever. 2002. Effects of abomasal vegetable oil infusion on splanchnic nutrient metabolism in lactating dairy cows. J. Dairy Sci. 85:1804-1814. https://doi.org/10.3168/jds.S0022-0302(02)74255 -0 .

Bergman, E. N., W. E. Roe, and K. Kon. 1966. Quantitative aspects of propionate metabolism and gluconeogenesis in sheep. Am. J. Physiol. 211:793-799. https://doi.org/10.1152/ajplegacy.1966.211 .3.793.

Demigné, C., C. Yacoub, C. Morand, and C. Rémésy. 1991. Interactions between propionate and amino acid metabolism in isolated sheep hepatocytes. Br. J. Nutr. 65:301-317. https://doi.org/10 $.1079 /$ BJN19910088.

Donkin, S. S., and L. E. Armentano. 1994. Regulation of gluconeogenesis by insulin and glucagon in the neonatal bovine. Am. J. Physiol. 266:R1229-R1237. https://doi.org/10.1152/ajpregu.1994 .266.4.R1229.

Donkin, S. S., and L. E. Armentano. 1995. Insulin and glucagon regulation of gluconeogenesis in preruminating and ruminating bovine. J. Anim. Sci. 73:546-551. https://doi.org/10.2527/1995.732546x.

Drackley, J. K., D. C. Beitz, and J. W. Young. 1991. Regulation of in vitro metabolism of palmitate by carnitine and propionate in liver from dairy cows. J. Dairy Sci. 74:3014-3024. https://doi.org/10 .3168/jds.S0022-0302(91)78487-7.

Fernandez, C. A., C. Des Rosiers, S. F. Previs, F. David, and H. Brunengraber. 1996. Correction of 13C mass isotopomer distributions for natural stable isotope abundance. J. Mass Spectrom. 31:255-262. https://doi.org/10.1002/(SICI)1096-9888(199603)31 $3<255:$ :AID-JMS290>3.0.CO $2-3$.

Garcia, M., B. J. Bequette, and K. M. Moyes. 2015. Hepatic metabolic response of Holstein cows in early and mid lactation is altered by nutrient supply and lipopolysaccharide in vitro. J. Dairy Sci. 98:7102-7114. https://doi.org/10.3168/jds.2014-9034.

Greenfield, R. B., M. J. Cecava, and S. S. Donkin. 2000. Changes in mRNA expression for gluconeogenic enzymes in liver of dairy cattle during the transition to lactation. J. Dairy Sci. 83:1228-1236. https://doi.org/10.3168/jds.S0022-0302(00)74989-7.

Gualdrón-Duarte, L. B., and M. S. Allen. 2017. Increased anaplerosis of the tricarboxylic acid cycle decreased meal size and energy intake of cows in the postpartum period. J. Dairy Sci. 100:44254434. https://doi.org/10.3168/jds.2016-12104.

Gualdrón-Duarte, L. B., and M. S. Allen. 2018. Fuels derived from starch digestion have different effects on energy intake and metabolic responses of cows in the postpartum period. J. Dairy Sci. 101:5082-5091. https://doi.org/10.3168/jds.2017-13607.

Hanson, R. W., and F. J. Ballard. 1967. The relative significance of acetate and glucose as precursors for lipid synthesis in liver and adipose tissue from ruminants. Biochem. J. 105:529-536. https:// doi.org/10.1042/bj1050529.

Hornung, R. W., and L. D. Reed. 1990. Estimation of average concentration in the presence of nondetectable values. Appl. Occup. Environ. Hyg. 5:46-51. https://doi.org/10.1080/1047322X.1990 .10389587.

Kelleher, J. K. 1986. Gluconeogenesis from labeled carbon: Estimating isotope dilution. Am. J. Physiol. 250:E296-E305. https://doi.org/ 10.1152/ajpendo.1986.250.3.E296.

Kennedy, K. M., and M. S. Allen. 2019a. Hepatic metabolism of propionate relative to meals for cows in the postpartum period. J. Dairy Sci. 102:7997-8010. https://doi.org/10.3168/jds.2018-15907.

Kennedy, K. M., and M. S. Allen. 2019b. The effect of uncouplers of oxidative phosphorylation on the feeding behavior of lactating dairy cows. J. Dairy Sci. 102:9767-9780. https://doi.org/10.3168/ jds.2019-16567.

Knapp, J. R., H. C. Freetly, B. L. Reis, C. C. Calvert, and R. L. Baldwin. 1992. Effects of somatotropin and substrates on patterns of liver metabolism in lactating dairy cattle. J. Dairy Sci. 75:10251035. https://doi.org/10.3168/jds.S0022-0302(92)77846-1.

Piantoni, P., C. M. Ylioja, and M. S. Allen. 2015. Feed intake is related to changes in plasma nonesterified fatty acid concentration and hepatic acetyl CoA content following feeding in lactating dairy cows. J. Dairy Sci. 98:6839-6847. https://doi.org/10.3168/jds.2014 $-9085$.

Previs, S. F., and D. E. Kelley. 2015. Tracer-based assessments of hepatic anaplerotic and TCA cycle flux: Practicality, stoichiometry, and hidden assumptions. Am. J. Physiol. Endocrinol. Metab. 309:E727-E735. https://doi.org/10.1152/ajpendo.00216.2015.

Reynolds, C. K., P. C. Aikman, B. Lupoli, D. J. Humphries, and D. E. Beever. 2003. Splanchnic metabolism of dairy cows during the transition from late gestation through early lactation. J. Dairy Sci. 86:1201-1217. https://doi.org/10.3168/jds.S0022-0302(03)73704 -7 .

Vazquez-Añon, M., S. Bertics, M. Luck, R. R. Grummer, and J. Pinheiro. 1994. Peripartum liver triglyceride and plasma metabolites in dairy cows. J. Dairy Sci. 77:1521-1528. https://doi.org/10 .3168/jds.S0022-0302(94)77092-2.

Wang, Z., and A. D. Jones. 2014. Profiling of stable isotope enrichment in specialized metabolites using liquid chromatography and multiplexed nonselective collision-induced dissociation. Anal. Chem. 86:10600-10607. https://doi.org/10.1021/ac502205y

Williamson, J. R., and R. H. Cooper. 1980. Regulation of the citric acid cycle in mammalian systems. FEBS Lett. 117(S1):K73-K85. https://doi.org/10.1016/0014-5793(80)80572-2. 
Wilson, K. A., Y. Han, M. Zhang, J. P. Hess, K. A. Chapman, G. W. Cline, G. P. Tochtrop, H. Brunengraber, and G. F. Zhang. 2017. Inter-relations between 3-hydroxypropionate and propionate metabolism in rat liver: Relevance to disorders of propionyl-CoA metabolism. Am. J. Physiol. Endocrinol. Metab. 313:E413-E428. https://doi.org/10.1152/ajpendo.00105.2017.

Wiltrout, D. W., and L. D. Satter. 1972. Contribution of propionate to glucose synthesis in the lactating and nonlactating cow. J. Dairy Sci. 55:307-317. https://doi.org/10.3168/jds.S0022-0302(72)85487 $-0$.

Young, J. W., S. L. Thorp, and H. Z. De Lumen. 1969. Activity of selected gluconeogenic and lipogenic enzymes in bovine rumen mucosa, liver and adipose tissue. Biochem. J. 114:83-88. https://doi .org/10.1042/bj1140083.
Zhang, Q., S. L. Koser, B. J. Bequette, and S. S. Donkin. 2015. Effect of propionate on mRNA expression of key genes for gluconeogenesis in liver of dairy cattle. J. Dairy Sci. 98:8698-8709. https://doi .org/10.3168/jds.2015-9590

\section{ORCIDS}

Katherine M. Kennedy ๑ https://orcid.org/0000-0003-3382-8376

Shawn S. Donkin @ https://orcid.org/0000-0003-3571-4946

Michael S. Allen @ https://orcid.org/0000-0002-7289-6382 